\begin{tabular}{|c|c|c|c|}
\hline Article Info & \multicolumn{2}{|c|}{\begin{tabular}{l|l} 
RESEARCH ARTICLE & ARAŞTIRMA MAKALESİ \\
\end{tabular}} & \\
\hline Title of Article & \multicolumn{2}{|c|}{$\begin{array}{l}\text { Investigation of Occupational Safety } \\
\text { Measures and Costs with Building } \\
\text { Information Modeling in Construction } \\
\text { Projects on a Case Study }\end{array}$} & \\
\hline $\begin{array}{l}\text { Corresponding } \\
\text { Author }\end{array}$ & \multicolumn{2}{|c|}{$\begin{array}{l}\text { Cemil AKÇAY } \\
\text { İstanbul Üniversitesi Mimarlık Fakültesi Mimarlık bölümü cakcay@ istanbul.edu.tr }\end{array}$} & \\
\hline $\begin{array}{l}\text { Received Date } \\
\text { Accepted Date }\end{array}$ & \multicolumn{2}{|l|}{$\begin{array}{l}02.11 .2021 \\
18.11 .2021\end{array}$} & \\
\hline DOI Number & \multicolumn{2}{|l|}{ https://doi.org/10.35674/kent.1018134 } & \\
\hline Author / Authors & $\begin{array}{l}\text { Cemil AKÇAY } \\
\text { Ömer GİRAN }\end{array}$ & $\begin{array}{l}\text { ORCID: 0000-0002-8216-8688 } \\
\text { ORCID: 0000-0003-4135-393X }\end{array}$ & \\
\hline How to Cite & \multicolumn{2}{|c|}{$\begin{array}{l}\text { AKÇAY, C. \& GİRAN, Ö. (2021). İnşaat Projelerinde Yapı Bilgi Modelleme İle İş̧ } \\
\text { Güvenliği Tedbirleri ve Maliyetlerinin Örnek Bir Vaka Üzerinden İncelenmesi, Kent } \\
\text { Akademisi, Volume, 14, Issue 4, 950-960. }\end{array}$} & $\begin{array}{l}\text { Kent Akademisi } \\
\text { Urban Academy }\end{array}$ \\
\hline
\end{tabular}

\title{
İnşaat Projelerinde Yapı Bilgi Modelleme ile İş Güvenliği Tedbirleri ve Maliyetlerinin Örnek Bir Vaka Üzerinden İncelenmesi
}

\begin{abstract}
:
Construction is a locomotive sector for the economies of developing countries. Occupational safety is very important in construction works, as it is one of the most dangerous business lines. The consequences of occupational accidents at construction sites may be quite severe. While one third of the fatal occupational accidents in our country occur in the construction sector, the majority of the said fatal occupational accidents are due to falling from height. In Turkey, which is located in the earthquake zone, building construction works have increased with the importance given to urban transformation in recent years. In particular, it is important to ensure the safety of both the employees, the other stakeholders in the construction sites, and the people passing by the construction environment in the building construction works carried out in the residential areas of the cities. In this study, the occupational safety measures to be taken during the construction of the work at the construction site were modeled with revit, which is one of the building information modeling software, in the pre-contract project phase in a case discussed and their costs were examined. In order to protect the employees and those around the construction site against the risks that may occur during the construction, the occupational safety measures required to be taken in the building were added to the created threedimensional model with a parametric design. Quantity information is automatically obtained from the defined objects. Costs were calculated by creating unit prices according to market rates and their ratio in total cost in $\mathrm{m}^{2}$ was found. By clicking on the created link or reading the QR Code, it is possible to navigate in the three-dimensional model and to see the measures taken.
\end{abstract}

KEYWORDS: Building Information Modeling, BIM, Occupational Safety, Cost, Parametric Design

${ }^{1}$ Istanbul University, Architecture Faculty, Architecture Department, cakcay@istanbul.edu.tr

${ }^{2}$ Istanbul University, Engineering Faculty, Civil Engineering Department, ogiran@iuc.edu.tr 


\section{ÖZ:}

İnşaat sektörü gelişmekte olan ülke ekonomileri için lokomotif bir sektördür. Çok tehlikeli iş kollarından biri olan inşaat işlerinde, iş güvenliği hususu oldukça önemlidir. Şantiyelerde gerçekleşen iş kazalarının sonuçları oldukça ağır olabilmektedir. Ülkemizde gerçekleşen ölümlü iş kazalarının üçte biri inşaat sektöründe meydana gelirken söz konusu ölümlü iş kazalarının büyük çoğunluğu ise yüksekten düşme sonucunda gerçekleşmektedir. Deprem kuşağında yer alan ülkemizde, son yıllarda kentsel dönüşüme verilen önemin artmasıyla birlikte bina yapım işleri de çoğalmıştır. Özellikle, kentlerin yerleşim bölgelerinde yapılan bina yapım işlerinde gerek çalışanların gerek şantiyelerde bulunan diğer paydaşların gerekse inşaat çevresinden geçenlerin güvenliğinin sağlanması önem arz etmektedir. Bu doğrultuda yapılan çalışmada, inşaat işlerinde şantiye sahasında işin yapımı sırasında alınması gerekli iş güvenliği tedbirleri, ele alınan bir vaka özelinde sözleşme öncesi projelendirme aşamasında yapı bilgi modellemesi yazılımlarından biri olan revit ile modellenmiş ve maliyetleri incelenmiştir. Oluşturulan üç boyutlu modele, inşaat sırasında oluşabilecek risklere karşı çalışanları ve şantiye çevresinde bulunanları korumak amacıyla yapıda alınması gerekli iş güvenliği tedbirleri parametrik tasarımla eklenmiştir. Tanımlanan objelerden metraj bilgisi otomatik olarak alınmıştır. Piyasa rayiçlerine göre birim fiyatlar oluşturularak maliyetler hesaplamış ve $\mathrm{m}^{2}$ olarak toplam maliyet içerisindeki oranı bulunmuştur. Oluşturulan linke tıklanarak veya Karekod okutularak üç boyutlu modelde gezinme ve alınan tedbirlerin görülmesi sağlanmıştır.

ANAHTAR KELIMELER: Yapı Bilgi Modelleme, YBM, İş Güvenliği, Maliyet, Parametrik Tasarım

\section{GİRIŞ}

İki yüze yakın alt sektörü destekleyen inşaat sektörü (TMB) gerek ülkemizde gerekse dünyada lokomotif sektörlerin başında gelmektedir. Tüik verilerine göre 2018 yılında gayri safi milli hasılanın (GSMH) \% 7.1'ini inşaat sektörü oluşturmaktadır (TÜIK). Covid 19 pandemisinin inşat sektörü üzerindeki olumsuz etkilerine rağmen 2020 yılında yaklaşık 272 milyar TL büyüklükle GSMH'nın \% 5.4'ünü sektör oluşturmuştur. Ülkemizde büyümede de etkin bir rol üstelenen inşaat sektörü istihdama katkı sağlamada da kilit rol üstlenmektedir (TÜiK). 2021 yılı ağustos ayı itibariyle sektörün istihdam oranı \% 6 civarında olurken sayı itibariyle 1,5 ila 2 milyon arasında yıllara göre değişen çalışan barındırmaktadır (TMB). Bu kadar fazla çalışanın olduğu ve inşaat işlerinin yürütüldüğü şantiye ortamında kısa veya uzun aralıklarla diğer paydaş çalışanların da varlığı düşünüldüğünde iş güvenliği ön plana çıkmaktadır. İnşaat sektörünün çok tehlikeli iş kollarından biri olmasının yanı sıra gerçekleşen iş kazalarının sonuçlarının ağır olması sektörün iş güvenliği açısından öne çıkmasının diğer sebeplerin biridir. Ülkemizin deprem kuşağında yer alması, beklenen İstanbul depremi, mevcut yapıların depreme karşı dayanıklı olmaması gibi sebeplerle kentsel dönüşümde tüm hızıyla gündemimize girmiştir. Yeni binaların yapılmasının yanı sıra kentsel dönüşümle mevut yapıların yıkılıp yeniden yapılması veya güçlendirilmesi, yine mevcut yapıların renovasyonunun sürekliliği yerleşim yerlerindeki inşaatlarda çevresel iş güvenliği tedbirlerinin ne denli önemli olduğunu gösteren diğer önemli bir faktördür.

Klasik yöntemde iş güvenliği ile ilgili önlemler inşaat sırasında alınmaktadır. Yine söz konusu iş güvenliği tedbirlerinin maliyeti ayrı bir kalem olarak hesaplanmayıp genel giderler içerisinde değerlendirilmektedir. Alınan bu önlemlere rağmen halen ölümlü iş kazalarının üçte biri inşaat sektöründe gerçekleşmektedir. Yapı bilgi modellemenin gelişimine paralel olarak tasarım aşamasında inşaatın tüm aşamaları modellenmekte ve simülasyonlarla inşaat aşamaları takip edilebilmektedir. Tüm inşaat disiplinine ait projelerinin üç boyutlu olarak tasarımının yapıldığı ve disiplinlerin birbiri olan ilişkilerinin ortaya konulabildiği yapı bilgi modelleme sisteminde yapım işlerinde inşaat alanında alınması gerekli çevresel iş güvenliği tedbirlerinin modellenerek sisteme entegre edilmesi malzeme metraj ve maliyet bilgilerinin otomatik olarak sistemden alınması mümkündür. Böylelikle tam bir proaktif yaklaşım sergilenmiş olacak iş kazalarının önlenmesi ile ilgili önlemlerin tasarım aşamasında planlanması sağlanacak ve işçilerin iş güvenliği ile ilgili eğitimlerine de pozitif katk1 verilmiş olacaktır.

\section{1. İş Sağlı̆̆g ve Güvenliği}

Dünya Sağlık Örgütü ve Uluslararası Çalışma Örgütü, iş sağlığı ve güvenliği kavramını "çalışanların sağlık kapasitelerini en yüksek düzeye çıkarmak, bu düzeyde devam ettirmek, işçilerin çalışma şartları yüzünden sağlıklarının bozulmasını engellemek, işçilerin çalıştırılmaları esnasında sağlığa aykırı etmenlerden oluşan tehlikeli durumlardan korumak, işçileri fizyolojik ve psikolojik durumlarına en uygun mesleki ortamlara yerleştirmek ve bu durumlarını sürekli hale getirmek" olarak tanımlar (WHO ve ILO). Bu çalışma da yukarıda tanımlanan işçilerin çalışması sırasında, çalışma ortamındaki tehlikeli durumların beraberinde getirebileceği risklerin ortadan kaldırılması için gerekli tedbirlerin alınması konusunda yapılmıştır. Bütün dünyada olduğu gibi ülkemizde de özellikle son yıllarda iş sağllğı ve güvenliği 
konusuna oldukça önem verilmektedir. İşs sağlığı güvenliği konusu, başlangıçta 4857 sayılı 4857 sayılı İş Kanununun bir bölümüyken 2012 yılında kabul edilen 6331 sayılı İş Sağlığı ve Güvenliği Kanunu ile ayrı bir kanun olarak düzenlenmiştir. Kanunun en önemli unsurlarından birisi getirdiği proaktif yaklaşımdır. Proaktif yaklaşımla "işyerinde veya işin yürütümü nedeniyle meydana gelen, ölüme sebebiyet veren veya vücut bütünlüğünü ruhen ya da bedenen engelli hâle getiren olay" (6331) iş kazalarının önüne geçilmesi hedeflenmektedir.

İşs sağlı̆̆ı ve güvenliği söz konusu olduğunda akla gelen ilk sektörlerden biri de inşaat sektörüdür. Aşağıda son üç yıl içerisinde gerçekleşen iş kazaları ile bu kazalar sonucu ölen işçi sayıları ile ilgili SGK tarafından yayımlanan istatistikler incelenerek sonuçlar Şekil 1 ve 2'de verilmiştir (SGK). Şekildeki grafiklere göre son üç yıl içerisinde ortalama gerçekleşen iş kazalarının \% 13,66'sı inşaat sektöründe meydana gelmiştir. İş kazası sonucu oluşan ölüm sayılarında inşaat sektörünün payı ise yaklaşık \% 33'dür. İnşaat sektöründe meydana gelen iş kazası oranı yaklaşık toplam iş kazasının 1/7,3 iken bu oran ölüm sayılarında 1/3 olarak gerçekleşmiştir. Bunun nedenleri inşaat sektörünün dinamik çalışma ortamı, inşaat sektöründe ağır ekipman kullanımı ve yoğun işçi çalıştırılmasından dolayı işçi-tehlike etkileşimleri gibi özelliklerdir (Khoshnava et al, 2012).

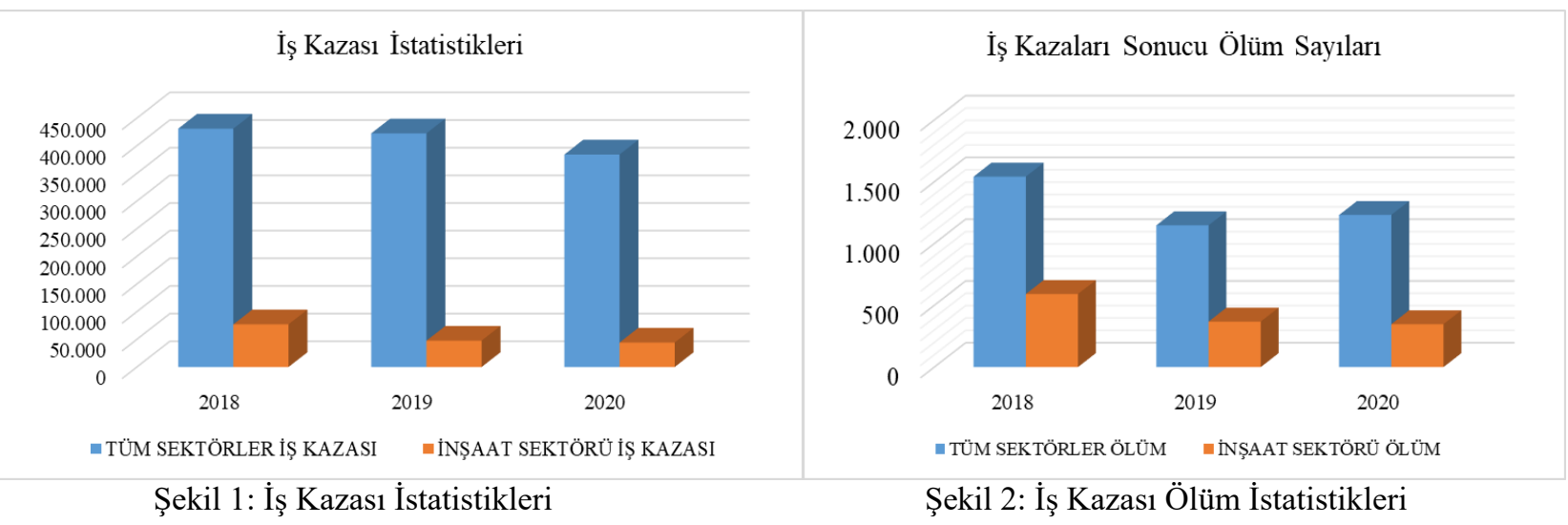

\section{2. İş Güvenliği Maliyetleri}

İş güvenliği ile ilgili maliyetleri; çalıştırılan iş güvenliği personeli maliyetleri, iş̧̧ilerin sağlık giderleri, iş güvenliği ile ilgili alınan tedbirlerin maliyeti, işçilerin kullandığı koruyucu ekipman maliyetleri başlıkları altında toplanmaktadır.

\subsection{1. İş Güvenliği Personel Maliyeti}

6331 sayılı İş Sağlığı ve Güvenliği Kanununun ilgili maddeleri doğrultusunda inşaat işlerinde çalıştırılan iş güvenliği uzmanı, işyeri hekimi ile diğer sağlık personeli maliyetleri bu başlık altında toplanabilir. Bu konuda çalıştırılacak personel sayısı, tehlike sınıfı ve çalışan işçi sayısına bağlı olarak yönetmeliklerle düzenlenmiştir.

\subsection{2. İşçilerin Sağlık Giderleri}

İşçilerin sağlık raporları ile periyodik olarak yapılan sağlık muayene maliyetleri ile çektirdikleri röntgen grafik ve yaptırdıkları tahlil maliyetleri işçilerin işle ilgili sağlık giderlerini oluşturmaktadır.

\subsubsection{Koruyucu Ekipman Maliyetleri}

İşçilerin işin yürütülmesi sırasında şantiye mahallinde oluşabilecek risklerden korunmak için giydikleri veya kullandıkları materyal maliyetleridir. Baret, iş güvenliği ayakkabısı, gözlük, emniyet kemeri vb. malzemeler koruyucu ekipmana örnek olarak verilebilir.

\subsection{4. Şantiye Mahalli Koruyucu Önlem Maliyetleri}

İnşaat işlerinde çalışma ortamında özellikle yüksekten düşmeyi önlemek için alınan korkuluk, bariyer güvenlik ağı gibi önlemlerin maliyetlerinden oluşur. Risk değerlendirmesindeki en önemli başlığı oluşturmaktadır. İnşaat sektöründe 
gerçekleşen iş kazalarının yarıya yakını yüksekten düşmeden oluşmaktadır (kaynak). Yüksekten düşme sonucu ciddi yaralanma ve ölüm riski mevcuttur. Bu çalışmada yüksekten düşmeyi engelleyecek tedbirler ile ilgili proaktif yaklaşımlar ve bunların maliyeti ele alınacaktır.

\subsection{Yapı Bilgi Modelleme (BIM)}

Yapı bilgi modelleme, tüm proje paydaşlarının ürettiği bilgi ve verinin depolanması, paylaşılması, birbiriyle iletişim kurması olarak tanımlanabilir. Teknolojinin gelişimine paralel olarak BIM bir dijital platforma dönüşmüştür (Karagöz, M., E.). BIM ile ilgili çok sayıda yazılım mevcuttur. Bu yazılımların yardımıyla tasarımdan yapının tamamlanması ve sonrasında işletilmesi diğer bir ifadeyle bir yapının tasarımından ekonomik ömrünü tamamlayıp yıkımına kadar geçen süreç BIM ile yürütülme imkânı bulmaktadır. Üç boyutlu tasarımın oluşturulması, inşaat simülasyonlarının yapılması, metraj maliyet bilgilerinin modelden elde edilmesi ve planlamanın yapılması BIM süreçleri içerisinde yer alır.

\subsection{Yapı Bilgi Modelleme İle İş Güvenliği}

İş güvenliği, genel inşaat verimliliğini etkileyen en kritik parametrelerden biridir. Önemli bir parametre olmasına rağmen inşaat proje yönetiminde hala ihmal edilen alanlardan biridir. Günümüzde etkin maliyet yönetimi, zaman yönetimi, kalite yönetimi gibi birçok inşaat alanında otomasyon gözlemlenmektedir; ancak iş güvenliği yönetimi için otomasyon, birçok inşaat firması tarafindan en az önceliğe sahiptir (Saeed et al, 2021).

İnşaat iş kazaları hem gelişmekte olan hem de gelişmiş ülkelerde, inşaat sektörlerinin karşılaştığı en yaygın sorundur. Ancak gelişmiş ülkeler inşaat kazalarını azaltmak için ileri teknolojileri benimsemektedir. Türkiye gibi gelişmekte olan ülkelerde ise iş sağlığı ve güvenliği alanında ileri teknolojilerin kullanımı pek yaygın değildir. Bu nedenle de inşaat iş kazalarının oranı yüksektir. (Lu et al, 2021).

20/6/2012 tarihli yönetmelik ve 6331 sayılı İş Sağlığ 1 ve Güvenliği Kanununun getirdiği sıkı tedbirlerin ardından müteahhitler şantiyelerdeki iş sağlığı ve güvenliği tehlikelerini azaltmak için iş güvenliği programları ve araçları uygulamaya başlamışlardır. Kullanılabilecek yeni araçlardan biri yapı bilgi modellemesidir (BIM). Literatürü incelediğimizde BIM'ın farklı iş güvenliği alanlarında uygulamasına rastlanmaktadır. Örneğin yüksekten düşme güvenliği, yangın güvenliği, genel risk değerlendirmesi, çalışma planı planlaması, işçi davranışı ve takibi gibi konularda BIM uygulaması çalışmaları yapılmıştır. Fakat BIM'ı kullanarak yapılan maliyet çalışmaları ile ilgili yeterli çalışma yoktur.

Zhang ve ark. 2015, yapının iş güvenliği planlaması için BIM tabanlı bir algılama ve düşme tehlikelerinden kaçınma yöntemi önermiştir. Bu çalışma, inşaat iş programına dahil edilen gizli düşme risklerinin planlama aşamasında fark edilip önlenebileceği konusunu araştırmaktadır. Ayrıca bina iş güvenliği ve BIM üzerine yapılan çalışmaların da bir tartışması yapılmıştır. Hara et al. 2019 çalışmasına göre; bina için iskele sistemlerinin otomatik tasarımı, planlanması ve çizimi ile iskelelerin yanlış yerleştirilmesi, sağlam olmayan ve ağıllığını taşıyamayan iskelelerden dolayı ortaya çıkan problemler BIM kullanarak çözülebilir. Kincelova et al. 2020, ahşap yapılarda yangından korunmak için BIM tabanlı otomatik kod kontrol tekniği geliştirilmiş̧ir. Shi ve ark. 2019 ve Khan et al. 2020 da yangın güvenliği için BIM işlevlerini kullanmışlardır.

Parn et al. 2019, kapalı alanlarda iş güvenliği yönetiminin dijitalleştirilmesini araştırmış olup hibrit bir Application Programming Interface (API) ile BIM'ın entegrasyonu üzerinde çalışmışlardır. Getuli et al. 2020 ise, yapı iş güvenliği planlamasında hem etkileşimli sanal gerçeklik hem de BIM teknolojilerini kullanarak bir bina yapım sürecini simüle etmişlerdir.

Jin et al. 2019, 4D BIM kullanarak inşaat risklerini değerlendirmek için bir sistem kurmuşlar. Bu yaklaşım, iş güvenlik riskini belirleme potansiyeline sahiptir ve tüm yüksek katlı projeler için inşaattan önce belirli bir süre, çalışma alanı ve iş güvenliği riskini tahmin eder. Tasarımcıların risk değerlendirmeleri yapmasına ve iş güvenliği ile ilgili mimari alternatifler seçmesine olanak tanır. Cortes-Perez, et al. 2020, İspanyol sağlık ve iş güvenliği yönetmelikleri tarafından öngörülen kriterlere uygun olarak tasarım sürecine entegrasyon için bir metodoloji geliştirmişlerdir.

$\mathrm{Bu}$ makalede tasarım aşamasında, şantiyelerdeki iş sağlığı ve güvenliği tehlikelerini azaltmak ve önlemek için kullanılabilecek yeni araçlardan biri olan yapı bilgi modellemesi (BIM) kullanılmıştır. Bu çalışma kapsamında BIM kavramı, özellikle inşaatta iş güvenliği ile ilgili kullanımları ve faydaları tanıtılmıştır. Vaka analizi olarak 5 katlı orta 
ölçekli gerçek bir inşaat projesinin tasarım aşamasında iş sağlığı ve güvenliği yasaları göz önüne alınarak iş güvenliği ile ilgili gereken uygulamalar modele dâhil edilerek maliyet çalışması yapılmıştır. Daha sonra planlama ve uygulama aşamasında alınmış olan önlemler izlenerek sonuçları değerlendirilmiştir.

\section{YÖNTEM}

İnşaat işlerinde şantiye sahasında işin yapımı sırasında alınması gerekli iş sağlığı ve güvenliği tedbirleri, ele alınan bir vaka özelinde sözleşme öncesi projelendirme aşamasında yapı bilgi modellemesi yazılımlarından biri olan revit ile modellenmiş ve maliyetleri incelenmiştir. Revit yazılımı ile yapı üç boyutlu olarak modellenmiştir. İş sağlığı ve güvenliği çerçevesinde alınması gereken önlemler tanımlanmış ve tanımlanan parametreler vasıtasıyla bilgiler eklenmiştir. Objelerden metraj bilgisi otomatik olarak alınmıştır. Piyasa rayiçlerine göre birim fiyatlar oluşturularak maliyetler hesaplamış ve $\mathrm{m}^{2}$ olarak toplam maliyet içerisindeki oranı bulunmuştur.

\section{1. İş Sağlığı ve Güvenliği Maliyetleri}

İş sağlığı ve güvenliği maliyetleri ülkemizde uygulanmakta olan 6331 Sayılı İş Sağlığı ve Güvenliği Kanunu kapsamında çalıştırılan iş sağlı̆̆ güvenliği uzmanı, işyeri hekimi, yardımcı personel gibi personel maliyetleri, çalışanların işe giriş ve periyodik sağlık muayeneleri, yine şantiyede çalışan işçilerin baret, ayakkabı, eldiven gözlük gibi kişisel koruyucu donanım ile şantiyede alınan güvenlik tedbirlerinden oluşmaktadır. Bu çalışmada üç boyutlu parametrik tasarımla bina projelendirme aşamasında iş güvenliği ile ilgili şantiyede alınan tedbirler ele alınmıştır. Bu tedbirler;

- Merdiven kenarları ile döşeme kenarlarına yapılan korkuluklar

- Şaft boşlukları korkuluk ve güvenlik ağları

- Döşeme kenarları güvenlik ağları

- Güvenlik tabelaları

\section{2. İş Sağlığı ve İş Güvenliği Model Çalışması}

Revit modelinden alınan renderların sanal gerçeklik dönüşümü ile katın içerisinde gezilip iş güvenliği tedbirlerinin yeterli olup olmadığı tespit edilmiştir. Aşağıdaki linke tıklanarak veya karekod okutularak ilgili model içerisinde gezilebilmektedir.

\subsection{1. İlgili link}

https://pano.autodesk.com/pano.html?mono=jpgs/66146359-85af-43e5-861c-b4019e5a5aac\&version=2

\subsection{2. İlgili karekod}

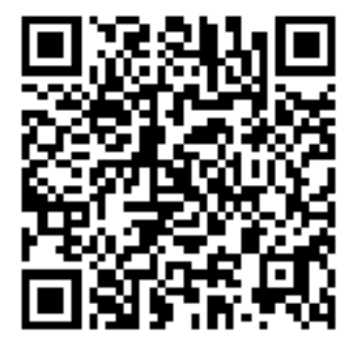

\section{BULGULAR}

$350.000 \mathrm{~m}^{2}$ kapalı alana sahip bir hastane yapısı üç boyutlu modellenmiştir. Şekil 3'de oluşturulan model görülmektedir. 


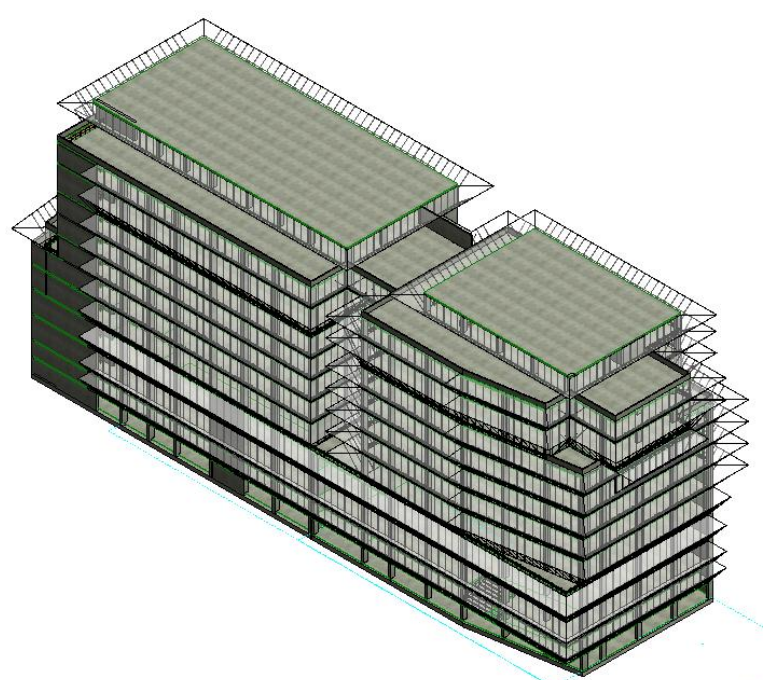

Şekil 3: Bina üç Boyutlu Revit Modeli

Oluşturulan modelde iş sağlığı ve güvenliği kapsamında binanın genelinde alınması gerekli önlemler parametrik olarak modele işlenmiştir. Bu önlemler; merdiven kenarlarına korkuluk yapılması, döşemedeki boşlukların kenarına düşeyde korkuluk yatayda ise güvenlik ağı yapılması, şaft boşluklarında da aynı tedbirlerin alınması, döşeme kenarlarına düşmeyi önleyecek şekilde korkuluk yapılması, yine döşeme kenarlarından dışarı doğru yukarıdan aşağı kalıp malzemesi vb. düşmesini engellemek için ağ gerilmesi, yine her katta uyarıcı güvenlik levhalarının konulmasıdır. Şekil 4'de modelden bir kesit görülmektedir.

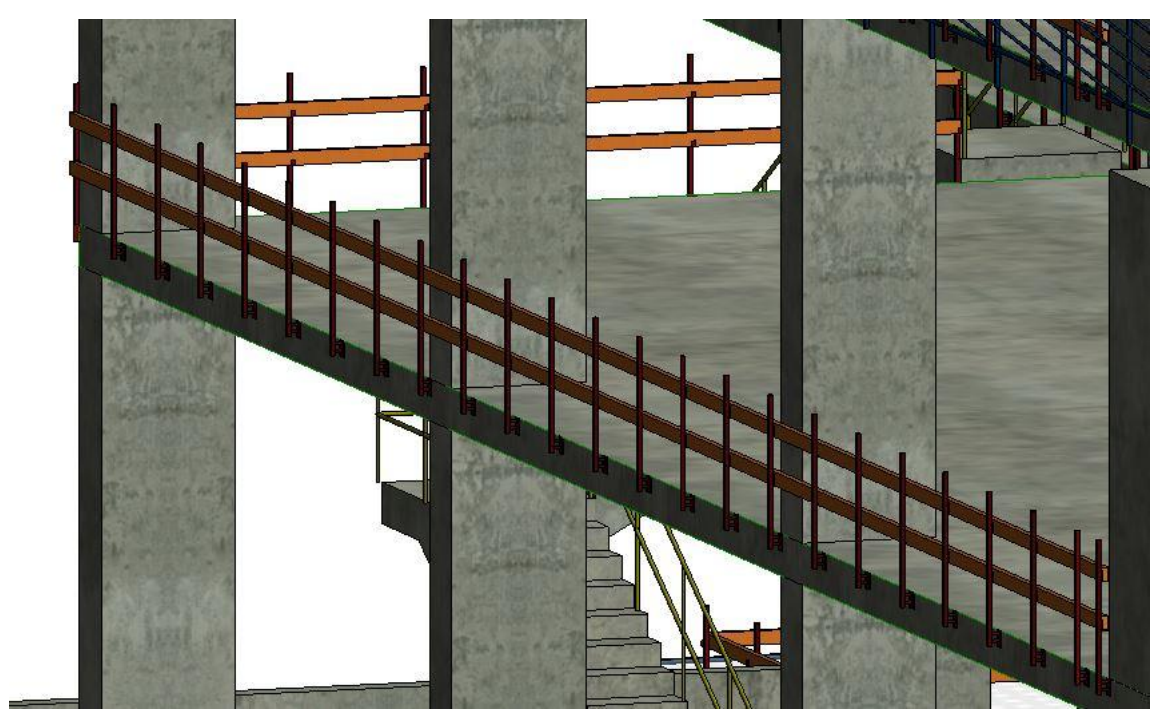

Şekil 4: Revit Modelinden Bir Kesit

\subsection{Döşeme ve Merdiven Kenarları Güvenlik Tedbirleri}

Merdiven ve döşeme kenarlarına yüksekten düşmeleri önlemek için en az bir metre yükseklikte korkuluk yapılması gerekmektedir. Modelde söz konusu korkuluklar standartlara uygun (TS-EN 13374) olarak yerleştirilmiştir. Şekil 5'de merdiven kenarlarına yapılan korkuluklar görülmektedir. 


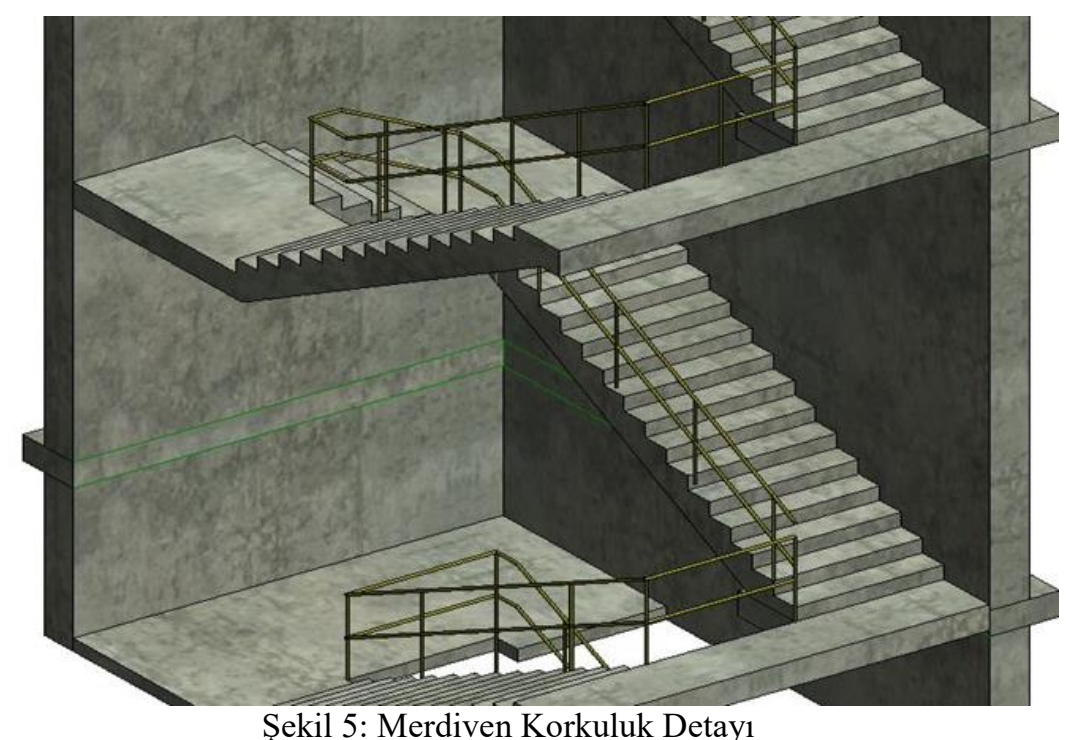

\subsection{Döşeme ve Şaft Boşlukları İş Güvenliği Tedbirleri}

Modelleme sırasında bina içerisinde bulunan döşemedeki asansör boşlukları gibi boşluklar ile şaft boşluklarının etrafına yüksekten düşmeyi önleyici en az bir metre yükseklikte dikey korkuluk ve yatayda ise güvenlik ağı yapılmıştır. Şekil 6'da korkuluk ve ağ detayları görülmektedir.

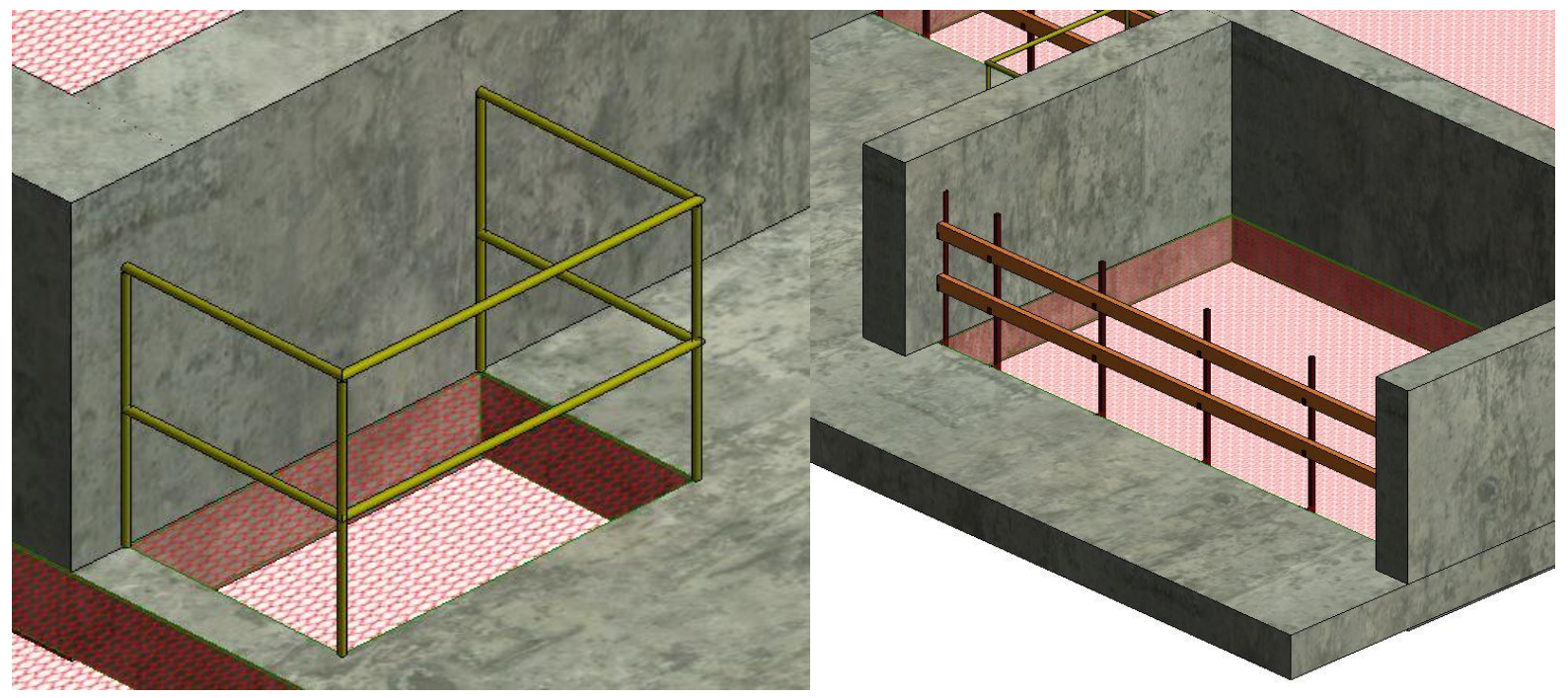

Şekil 6: Döşeme ve Şaft Korkuluk ve Ağ Detayı

\subsection{Döşeme Kenarları İş Güvenliği Tedbirleri}

Yapıların döşeme kenarlarına yapılan konstrüksiyonla uygulanan güvenlik ağları ile çalışanların yüksekten düşmesine karşı güvenlik sağlanmanın yanı sıra üst katlarda düş̧ecek malzemelerin çalışanlar veya aşağıdan geçen insanlar için tehlike oluşturmasının da önüne geçilmektedir. Ağların TS En 1263-1 ve 2 standartlarına uygun olması gerekmektedir. Modelde yapılan ağ sisteminin detayı Şekil 5'de verilmiş̧ir. 


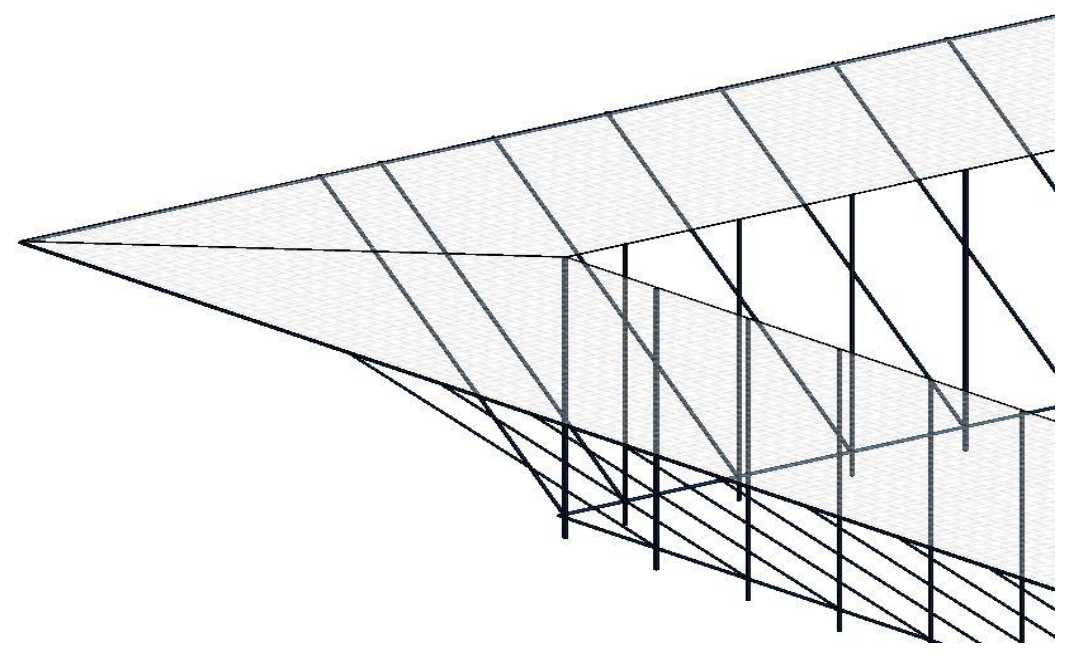

Şekil 7: Güvenlik Ağı Detay Görüntüsü

\subsection{Güvenlik Levhaları}

İnşaat işlerinde kırmızı renk ile yasaklayıcı levhalar ve yangın levhaları; örneğin sigara içmek yasaktır, mavi renk ile emredici levhalar; örneğin dikkat iş gözlüğü kullan, yeşil ile acil çıkış levhaları; örnek toplanma noktası, sarı ile uyarıcı levhalar; örneğin dikkat kaygan zemin gibi iş güvenliği levhaları duvarlara asılmaktadır. Modelde her katta söz konusu yasaklayıcı, uyarıcı ve emredici iş güvenliği levhaları uygun yerlere yerleştirilmiştir. Şekil 8'de söz konusu levhalar görülmektedir.

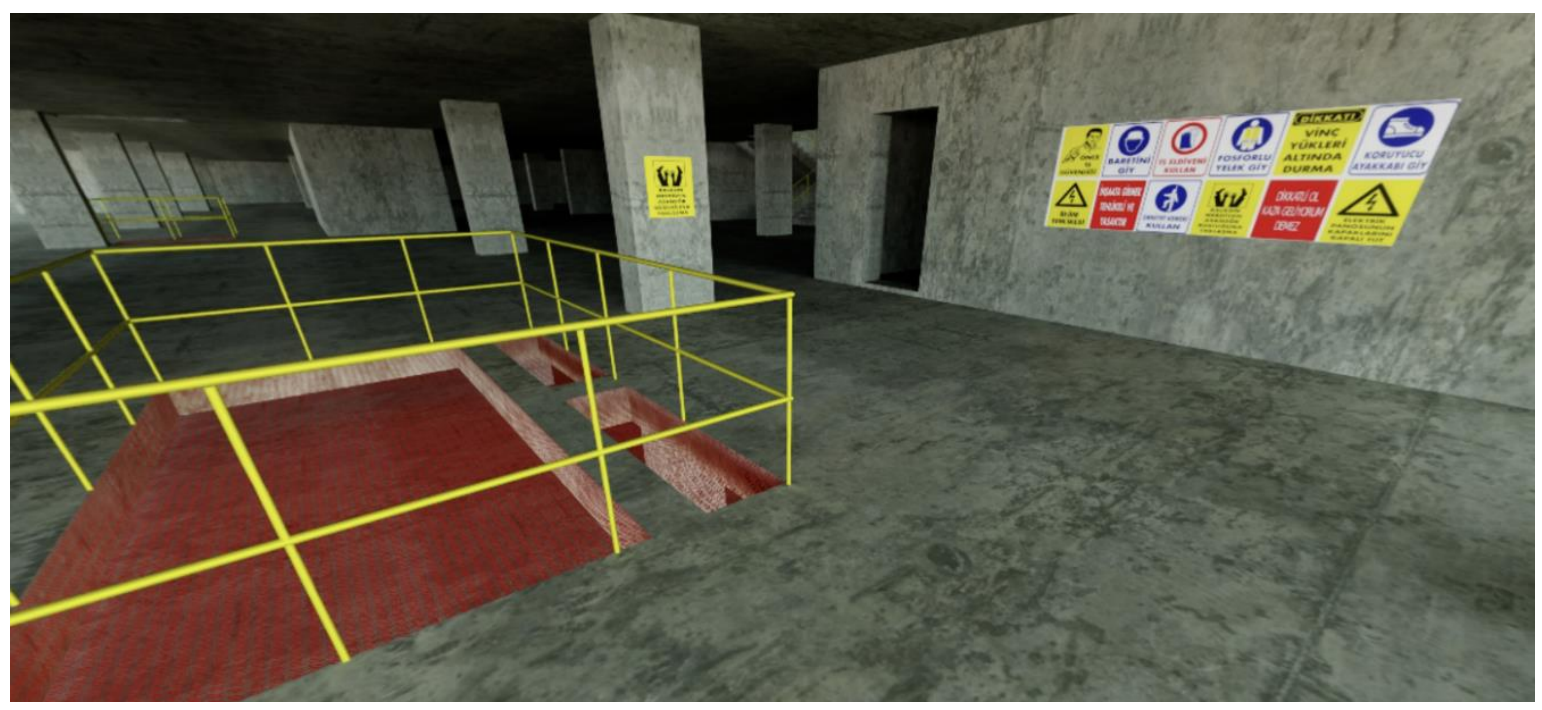

Şekil 8: İş Güvenliği Levhaları

\section{5. İş Güvenliği Maliyetleri}

İnşaata başlamadan projelendirme aşamasında üç boyutlu olarak parametrik modellenen iş güvenliği tedbirlerinin maliyet hesabı yapılmıştır. Söz konusu maliyet hesabına esas metrajlar programdan otomatik olarak çekilmiştir. Birim fiyatlar ise piyasa fiyatları ile analiz edilerek bulunmuştur. Tablo 1'de söz konusu maliyetler verilmiştir. 
Tablo 1: İş Güvenliği Maliyetleri

\begin{tabular}{|c|c|c|c|c|c|}
\hline & Iş Güvenliği Tedbirleri & Birim & Metraj & Birim Fiyat-TL & Toplam Fiyat-TL \\
\hline 1 & Döşeme ve Şaft Boşluğu Korkuluk & $\mathrm{mt}$ & 2637 & 92 & 242.604 \\
\hline 2 & Merdiven Kenarı Korkuluk & $\mathrm{mt}$ & 1042 & 92 & 95.864 \\
\hline 3 & Döşeme ve Şaft Boşluğu Güvenlik Ağı & $\mathrm{m} 2$ & 2030 & 55 & 111.650 \\
\hline 4 & Döşeme Kenarı Güvenlik Ağı (4m) & $\mathrm{mt}$ & 850 & 256 & 217.600 \\
\hline 5 & Güvenlik Levhaları & $\mathrm{ad}$ & 440 & 15 & 6.600 \\
\hline \multicolumn{2}{|c|}{ GENEL TOPLAM } & & 674.318 \\
\hline
\end{tabular}

Söz konusu maliyetler toplam kapalı alana oranlandığında birim iş güvenliği maliyetleri elde edilmiş ve tablo 2'de verilmiştir.

Tablo 2: $\mathrm{m}^{2}$ İş Güvenliği Maliyetleri

\begin{tabular}{|c|c|c|}
\hline Toplam Kapalı Alan-m2 & ISG Maliyet-TL & m2 Maliyet-TL \\
\hline 350.000 & 674.318 & 1,93 \\
\hline
\end{tabular}

Toplam inşaat maliyeti hesaplanmış ve iş güvenliği maliyetlerinin söz konusu maliyete oranı tablo 3'de hesaplanmış ve grafik olarak şekil 9'da verilmiştir.

Tablo 3: İş Güvenliği Maliyetleri / Toplam İnşaat Maliyeti

\begin{tabular}{|c|c|c|c|}
\hline Toplam Kapalı Alan-m2 & Toplam İnşaat Maliyeti-TL & $\begin{array}{c}\text { Toplam İSG Maliyeti- } \\
\text { TL }\end{array}$ & $\begin{array}{c}\text { ISG Maliyet/İnşaat } \\
\text { Maliyeti }\end{array}$ \\
\hline 350.000 & 2.800 .000 .000 & 674.318 & $0,02 \%$ \\
\hline
\end{tabular}

\section{isG Maliyet / Toplam Maliyet}

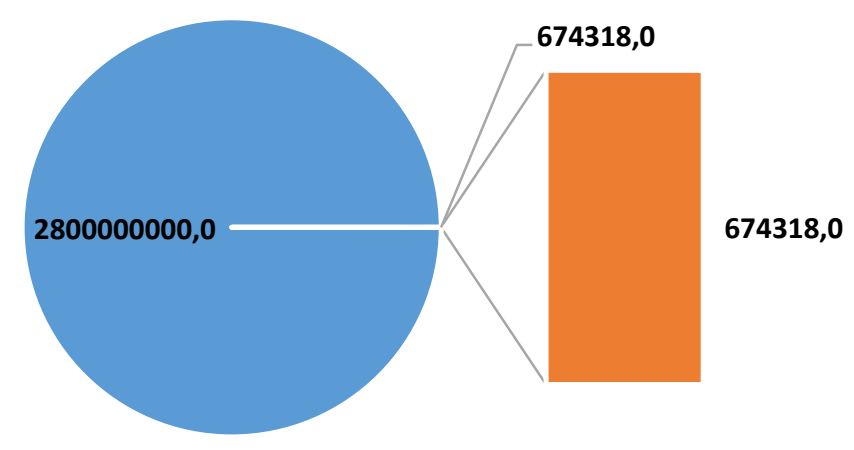

- Toplam İnşaat Maliyeti-TL = Toplam isG Maliyeti-TL

Şekil 9: İş Güvenliği Maliyeti / Toplam İnşaat Maliyeti Grafiği

\section{DEĞERLENDİRME VE SONUÇ}

Ülkemizde uygulanmakta olan 6331 sayılı İş Sağlığı ve Güvenliği Kanununun çalışma hayatına getirdiği en önemli yaklaşım proaktif yaklaşımdır. Klasik yaklaşımın aksine uygulamada iş güvenliği uzmanları tarafından şantiyede risk analizi yapılarak olası iş kazalarının önüne geçilebilmesi için gerekli önlemlerin alınması amaçlanmaktadır. İş güvenliği adına alınması gerekli tedbirler için ise maliyet çalışması sırasında herhangi bir çalışma yapılmamaktadır. Söz konusu maliyetler birim fiyatlar içerisindeki \% 25 yüklenici kârı ve genel giderler içerisinde değerlendirilmektedir. Kanunun 
ön plana çıkardığı proaktif yaklaşıma inşaat işlerinde yapı bilgi modelleme çok iyi bir örnek teşkil etmektedir. Yapı bilgi modelleme ile inşaatta faaliyetler başlamadan tasarım aşamasında bilgisayar programları aracıllı̆ııla tüm disiplinlere ait üç boyutlu tasarım yapılmaktadır. İş güvenliği ile ilgili alınması gerekli tedbirler parametrik olarak tasarıma eklenebilmektedir. Bu doğrultuda bu çalışmada da $350.000 \mathrm{~m}^{2}$ hastane yapısının revit ile üç boyutlu modeli çıkartılmıştır. İş güvenliği ile ilgili inşaat mahallinde alınması gerekli tedbirler olan;

- Merdiven kenarlarına korkuluk yapılması,

- Şaft ve döşeme boşluk kenarlarına korkuluk yapılması,

- Şaft ve döşeme boşluklarına güvenlik ağı yapılması,

- Döşeme kenarlarına korkuluk yapılması,

- Döşeme kenarlarına güvenlik ağı yapılması,

- Yasaklayıcı, uyarıcı ve emredici uyarı levhaların konulması.

Parametrik tasarım ile modele eklenmiştir. Oluşturulan sanal gerçeklik dönüşümü ile üç boyutlu model içerisinde gezinti yapılarak tedbirlerin kontrol edilebilmesi imkânı tanınmış, uygulama sırasında iş güvenliği uzmanları ile saha mühendislerinin yapılan imalat ile yapılması gerekeni görsel olarak da kıyaslayabilmesi sağlanmıştır. Modelden direkt metraj ve malzeme bilgisi alınarak yapılacak imalatın metrajı otomatik olarak hesaplanmıştır. Söz konusu tedbirlerin birim fiyatları oluşturularak maliyetleri hesaplanmıştır. İSG birim $\mathrm{m}^{2}$ maliyeti 1,93 TL bulunmuştur. İSG maliyetinin toplam inşaat maliyeti içerisindeki oranı ise \% 0,02 olarak hesaplanmıştır. Böylece ihale öncesinde hem yaklaşık maliyet hesaplanırken hem de ihale teklifi verilirken göz önüne alınmayan maliyetlerin görünür olması sağlanmıştır.

Dünyada geniş bir kullanım alanına sahip, ülkemizde de yeni yeni kullanılmaya başlanan yapı bilgi modelleme ile yapılacak benzer çalışmaların farklı projelerde uygulanması ile iş sağlığı ve güvenliğinde iş kazalarının önüne geçilebilmesi için en önemli etken olan proaktif yaklaşımların çok daha rasyonel bir şekilde uygulama imkânı bulacağı ve maliyetlerin de daha sağlıklı bir şekilde ortaya konulabileceği değerlendirilmiştir.

\section{Etik Standart ile Uyumluluk}

Çıkar Çatışması: Yazarlar herhangi bir çıkar çatışmasının olmadığını beyan eder.

Etik Kurul İzni: Bu çalışma için etik kurul iznine gerek yoktur.

Finansal Destek: Finansal destek bulunmamaktadır.

Teşekkür: Hastane yapısının revit modelinin oluşturulmasında destek sağlayan Prota Mühendislik Proje ve Danışmanlık Hizmetleri A.Ş.'ne teşekkür ederiz.

\section{KAYNAKÇA}

6331, İş Sağlığ1 ve Güvenliği Kanunu. Erişim Adresi : https://www.mevzuat.gov.tr/MevzuatMetin/1.5.6331.pdf, ziyaret tarihi $15 / 08 / 2021$

Getuli, V., Capone, P., Bruttini, A., \& Isaac, S. (2020). BIM-based immersive Virtual Reality for construction workspace planning: A safety-oriented approach. Automation in Construction, 114, 103160.

Hara, T., Shimomura, K., Hamano, K., \& Miyake, S. (2019). Automatic design, planning and drawing of scaffolding system for constructions. Advances in computational design, 4(2), 179-196.

https://data.tuik.gov.tr/Bulten/Index?p=Quarterly-Gross-Domestic-Product-Quarter-IV:-October-December,-202037180

ILO (2015), Investigation of occupational accidents and diseases- a practical guide for labour inspectors. Geneva: International Labour Office.

International Labour Organization, Erişim Adresi: https://www.ilo.org ziyaret tarihi 15/09/2021

Karagöz, M., E. (2019). Bim İle Yapı Yaklaşık Maliyet Hesaplama Önerisi. Yapı Bilgi Modelleme Dergisi, Sayı: 1 S. $39-45$. 
Khan, N., Ali, A. K., Van-Tien Tran, S., Lee, D., \& Park, C. (2020). Visual language-aided construction fire safety planning approach in building information modeling. Applied Sciences, 10(5), 1704.

Khoshnava, S., Ahankoob, A., Preece, C., \& Rostami, R. (2012, December). Application of BIM in construction safety. In Management in Construction Research Association (MiCRA), Postgraduate Conference, University Teknologi Malaysia, Malaysia.

Kincelova, K., Boton, C., Blanchet, P., \& Dagenais, C. (2020). Fire safety in tall timber building: A BIM-based automated code-checking approach. Buildings, 10(7), 121.

Lu, Y., Gong, P., Tang, Y., Sun, S., \& Li, Q. (2021). BIM-integrated construction safety risk assessment at the design stage of building projects. Automation in Construction, 124, 103553.

Parn, E. A., Edwards, D., Riaz, Z., Mehmood, F., \& Lai, J. (2019). Engineering-out hazards: Digitising the management working safety in confined spaces. Facilities.

Roberts, C. J., Edwards, D. J., Hosseini, M. R., Mateo-Garcia, M., \& Owusu-Manu, D. G. (2019). Post-occupancy evaluation: a review of literature. Engineering, Construction and Architectural Management.

Saeed, Y., Aziz, E., \& Zelentsov, L. (2021). Technology role in safety management of Iraqi construction projects. In E3S Web of Conferences (Vol. 263, p. 04043). EDP Sciences.

Shi, J., Dao, J., Jiang, L., \& Pan, Z. (2019). Research on IFC-and FDS-based information sharing for building fire safety analysis. Advances in Civil Engineering.

Sosyal Güvenlik Kurumu (SGK). http://www.sgk.gov.tr/wps/portal/sgk/tr/kurumsal/istatistik/sgk_istatistik_yilliklari, ziyaret tarihi 22/09/2021.

Türkiye İstatistik Kurumu (TÜİK).

Türkiye Müteahhitler Birliği (TMB).

https://www.tmb.org.tr/uploads/publications/60e6b78ded6d830993d559a1/1625751949522-tmb-bulten-temmuz2021.pdf.

World Health Organization, (2002), Good Practice in Occupational Health Services: A Contrubition to Workplace Health.

World Health Organization, Erişim Adresi: https://www.who.int/ ziyaret tarihi 15/09/2021

Yazdani-Chamzini, A., Razani, M., Yakhchali, S. H., Zavadskas, E. K., \& Turskis, Z. (2013). Developing a fuzzy model based on subtractive clustering for road header performance prediction. Automation in Construction, 35, 111-120.

Zhang, S., Sulankivi, K., Kiviniemi, M., Romo, I., Eastman, C. M., \& Teizer, J. (2015). BIM-based fall hazard identification and prevention in construction safety planning. Safety science, 72, 31-45. 